\title{
THE RELATIONSHIP OF PLASMA PH AND ANION PATTERN TO MERCURIAL DIURESIS ${ }^{1}$
}

\author{
BY D. R. AXELROD AND R. F. PITTS \\ (From the Departments of Physiology, Syracuse University College of Medicine, Syracuse, N. Y., \\ and Cornell University Medical College, New York, N. Y.)
}

(Submitted for publication July 23, 1951; accepted November 5, 1951)

In 1925 Keith, Barrier and Whelan (1) noted that the diuretic potency of novasurol was increased when ammonium chloride was administered prior to the mercurial. This observation was subsequently extended to include potentiation of other mercurial diuretics by a variety of acidifying agents (2-5). Furthermore, potentiation has been shown to be synergistic for fluid loss induced by the combination exceeds the sum of the losses induced by the agents singly $(2,3,5,6)$. Potentiation has been variously ascribed to the following changes induced by the acidifying agents: increased acidity of the body fluids (2, $4,5)$, increased acidity of the urine $(7)$ and altered anion pattern of the blood plasma $(4,8,9)$. Experiments described below suggest that the latter is the most significant factor and, possibly alone, can account for the observed increase in diuretic efficacy.

\section{METHODS}

All experiments were performed on two well trained female dogs, loosely restrained on a comfortable animal board. Creatinine for the measurement of glomerular filtration rate and para-aminohippurate for the measurement of minimum effective renal plasma flow were infused intravenously at a rate calculated to maintain plasma concentrations constant at optimum levels. The animals were fasted for 14 to 16 hours preceding an experiment, and 30 minutes prior to the start of the first collection period, $500 \mathrm{cc}$. of water were administered by stomach tube. After one or more control periods, salyrgan ${ }^{2}$ was given intravenously. Since mercury diuresis was superimposed on water diuresis, little emphasis has been placed on urine flow. Rather diuretic efficacy has been assessed in terms of rates of excretion of sodium and chloride.

Urine was collected under paraffin oil by an indwelling urethral catheter and the bladder was emptied by firm, gentle, suprapubic pressure. Aliquots for carbon dioxide and $\mathrm{pH}$ determinations were withdrawn without exposure to air. Blood samples were collected by an in-

1 These studies were supported by grants from the $\mathrm{Na}$ tional Heart Institute, National Institutes of Health and the Life Insurance Medical Research Fund.

2 We wish to thank Winthrop-Stearns, Inc., for their generous supply of salyrgan. dwelling needle in the femoral artery. That part of the sample to be used for $\mathrm{pH}$ and carbon dioxide determinations was drawn in an oiled syringe and handled anaerobically. Measurements of blood and urine $\mathrm{pH}$ were made at room temperature with a Cambridge condenser type glass electrode and corrected to $38^{\circ}$ by subtracting .01 $\mathrm{pH}$ unit per degree difference in temperature. Bicarbonate was calculated from the carbon dioxide content and $\mathrm{pH}$ using the Henderson-Hasselbalch equation. Carbon dioxide was determined by the method of Van Slyke and Sendroy (10), chloride by the Van Slyke and Hiller modification of Sendroy's method (11), sodium and potassium on an internal standard flame photometer and creatinine (12) and para-aminohippurate (13) colorimetrically.

\section{RESULTS}

Three experiments on one dog are summarized in Table I. In each experiment $80 \mathrm{mg}$. of mercury as salyrgan were administered intravenously at zero time. The first experiment describes the more or less typical response of this animal to the mercurial diuretic alone and serves as a standard of reference with which the response under other conditions may be compared. In this experiment sodium excretion increased from 247 microequivalents per minute in the control period to 744 microequivalents per minute some 60 to 80 minutes after the diuretic; an increase of about 500 microequivalents per minute.

On the day preceding the second experiment 10 gms. of ammonium chloride were given orally in divided doses. The inherent diuretic action of the salt was largely spent on the succeeding day, for the control rates of sodium excretion averaged but 48 microequivalents per minute. However,

3 The chloride ion, left after the ammonia has been converted into urea by the liver, is neutralized by base derived from bicarbonate and is partially excreted by the kidney as sodium chloride. This loss of sodium chloride and its associated water we consider a consequence of the inherent diuretic action of ammonium chloride. It is relatively short-lived in comparison with the more prolonged disturbance in plasma anion pattern and $\mathrm{pH}$ occasioned by the salt. 
D. R. AXELROD AND R. F. PITTS

TABLE I

A comparison of the diuretic responses to salyrgan under conditions of normal acid base balance and acidosis induced by ingestion of ammonium chloride and by inhalation of 6.5 per cent carbon dioxide in air. Dog $R$

\begin{tabular}{|c|c|c|c|c|c|c|c|c|c|c|c|c|c|}
\hline \multirow{2}{*}{ Time } & \multirow{2}{*}{$\begin{array}{l}\text { Urine } \\
\text { flow }\end{array}$} & \multicolumn{2}{|c|}{ Clearance } & \multicolumn{4}{|c|}{ Plasma concentration } & \multicolumn{2}{|c|}{$\mathrm{pH}$} & \multicolumn{4}{|c|}{ Rate of excretion } \\
\hline & & $\begin{array}{l}\text { Creat- } \\
\text { inine }\end{array}$ & PAH & $\mathrm{Na}$ & $\mathbf{K}$ & $\mathbf{C l}$ & $\mathrm{HCO}_{2}$ & Plasma & Urine & $\mathrm{Na}$ & $\mathbf{K}$ & $\mathbf{C l}$ & HCO, \\
\hline mins. & cc./min. & \multicolumn{2}{|c|}{$c c . / m i n}$. & \multicolumn{4}{|c|}{ milliEq./liter } & & & \multicolumn{4}{|c|}{ microEg./min. } \\
\hline \multicolumn{14}{|c|}{ Salyrgan alone } \\
\hline$-20-0$ & 3.00 & 80.3 & 446 & 149 & 2.8 & 118 & 21.3 & 7.47 & 7.12 & 247 & 76.6 & 234 & 38.4 \\
\hline \multicolumn{14}{|c|}{$80 \mathrm{mg} . \mathrm{Hg}$ as salyrgan } \\
\hline $\begin{array}{c}0-20 \\
20-40 \\
40-60 \\
60-80 \\
80-100 \\
100-120\end{array}$ & $\begin{array}{l}3.80 \\
3.45 \\
4.70 \\
6.05 \\
4.65 \\
3.15\end{array}$ & $\begin{array}{l}80.7 \\
75.6 \\
68.4 \\
64.6 \\
58.2 \\
53.7\end{array}$ & $\begin{array}{l}477 \\
423 \\
414 \\
412 \\
370 \\
383\end{array}$ & $\begin{array}{l}148 \\
148 \\
148 \\
149 \\
148 \\
147\end{array}$ & $\begin{array}{l}3.1 \\
2.4 \\
2.4 \\
3.0 \\
2.9 \\
2.5\end{array}$ & $\begin{array}{l}117 \\
116 \\
115 \\
115 \\
113 \\
113\end{array}$ & $\begin{array}{l}21.1 \\
21.0 \\
19.6 \\
20.7 \\
20.8 \\
20.5\end{array}$ & $\begin{array}{l}7.44 \\
7.45 \\
7.47 \\
7.46 \\
7.44 \\
7.46\end{array}$ & $\begin{array}{l}\mathbf{7 . 1 3} \\
\mathbf{6 . 3 6} \\
\mathbf{5 . 8 1} \\
\mathbf{5 . 7 0} \\
\mathbf{5 . 6 0} \\
\mathbf{5 . 5 7}\end{array}$ & $\begin{array}{l}362 \\
372 \\
580 \\
744 \\
538 \\
331\end{array}$ & $\begin{array}{l}55.9 \\
40.7 \\
42.9 \\
44.1 \\
41.9 \\
39.7\end{array}$ & $\begin{array}{l}326 \\
408 \\
566 \\
815 \\
610 \\
388\end{array}$ & $\begin{array}{c}48.6 \\
8.60 \\
2.60 \\
2.43 \\
1.20 \\
0.72\end{array}$ \\
\hline \multicolumn{14}{|c|}{ Salyrgan plus $\mathrm{NH}_{4} \mathrm{Cl}$} \\
\hline $\begin{array}{l}-40-20 \\
-20-0\end{array}$ & $\begin{array}{l}1.50 \\
1.05\end{array}$ & $\begin{array}{l}90.5 \\
72.2\end{array}$ & $\begin{array}{l}364 \\
344\end{array}$ & $\begin{array}{l}146 \\
144\end{array}$ & $\begin{array}{l}3.0 \\
2.9\end{array}$ & $\begin{array}{l}117 \\
115\end{array}$ & $\begin{array}{l}15.4 \\
14.5\end{array}$ & $\begin{array}{l}7.36 \\
7.36\end{array}$ & $\begin{array}{l}5.39 \\
5.52\end{array}$ & $\begin{array}{l}60 \\
36\end{array}$ & $\begin{array}{l}45.8 \\
35.6\end{array}$ & $\begin{array}{r}133 \\
83\end{array}$ & $\begin{array}{l}0.26 \\
0.27\end{array}$ \\
\hline \multicolumn{14}{|c|}{$80 \mathrm{mg} . \mathrm{Hg}$ as salyrgan } \\
\hline $\begin{array}{c}0-20 \\
20-40 \\
40-60 \\
60-80 \\
80-100 \\
100-120\end{array}$ & $\begin{array}{r}3.30 \\
11.40 \\
10.40 \\
5.50 \\
3.10 \\
3.00\end{array}$ & $\begin{array}{r}100.7 \\
86.5 \\
81.9 \\
61.6 \\
54.8 \\
54.3\end{array}$ & $\begin{array}{l}492 \\
405 \\
388 \\
268 \\
236 \\
227\end{array}$ & $\begin{array}{l}145 \\
145 \\
146 \\
146 \\
150 \\
151\end{array}$ & $\begin{array}{l}2.7 \\
2.8 \\
2.9 \\
2.9 \\
2.8 \\
2.9\end{array}$ & $\begin{array}{l}121 \\
120 \\
119 \\
118 \\
121 \\
120\end{array}$ & $\begin{array}{l}14.6 \\
14.7 \\
13.9 \\
14.0 \\
14.9 \\
15.3\end{array}$ & $\begin{array}{l}7.37 \\
7.40 \\
7.42 \\
7.42 \\
7.41 \\
7.41\end{array}$ & $\begin{array}{l}\mathbf{5 . 6 7} \\
\mathbf{5 . 4 9} \\
\mathbf{5 . 3 4} \\
\mathbf{5 . 2 1} \\
\mathbf{5 . 1 2} \\
\mathbf{5 . 1 5}\end{array}$ & $\begin{array}{r}349 \\
1,510 \\
1,410 \\
690 \\
320 \\
310\end{array}$ & $\begin{array}{l}72.3 \\
67.2 \\
64.5 \\
54.5 \\
48.0 \\
45.9\end{array}$ & $\begin{array}{r}445 \\
1,631 \\
1,575 \\
820 \\
434 \\
407\end{array}$ & $\begin{array}{l}0.94 \\
2.01 \\
1.31 \\
0.53 \\
0.27 \\
0.38\end{array}$ \\
\hline \multicolumn{14}{|c|}{ Salyrgan plus $\mathrm{CO}_{2}$} \\
\hline $\begin{array}{l}-40-20 \\
-20-0\end{array}$ & $\begin{array}{l}1.40 \\
1.60\end{array}$ & $\begin{array}{l}78.4 \\
82.6\end{array}$ & $\begin{array}{l}346 \\
328\end{array}$ & $\begin{array}{l}149 \\
148\end{array}$ & $\begin{array}{l}3.02 \\
2.87\end{array}$ & $\begin{array}{l}115 \\
114\end{array}$ & $\begin{array}{l}23.4 \\
25.3\end{array}$ & $\begin{array}{l}7.28 \\
7.28\end{array}$ & $\begin{array}{l}7.46 \\
7.52\end{array}$ & $\begin{array}{l}147 \\
214\end{array}$ & $\begin{array}{l}31.8 \\
36.0\end{array}$ & $\begin{array}{l}126 \\
171\end{array}$ & $\begin{array}{l}22.6 \\
42.3\end{array}$ \\
\hline \multicolumn{14}{|c|}{$80 \mathrm{mg} . \mathrm{Hg}$ as salyrgan } \\
\hline $\begin{array}{c}0-20 \\
20-40 \\
40-60 \\
60-80 \\
80-100 \\
100-120\end{array}$ & $\begin{array}{l}1.90 \\
4.60 \\
5.70 \\
4.75 \\
3.30 \\
2.80\end{array}$ & $\begin{array}{l}82.7 \\
94.3 \\
82.7 \\
77.6 \\
71.8 \\
67.1\end{array}$ & $\begin{array}{l}314 \\
312 \\
268 \\
261 \\
250 \\
242\end{array}$ & $\begin{array}{l}149 \\
150 \\
148 \\
149 \\
147 \\
150\end{array}$ & $\begin{array}{l}2.69 \\
2.80 \\
2.91 \\
2.91 \\
2.83 \\
2.90\end{array}$ & $\begin{array}{l}113 \\
116 \\
113 \\
111 \\
107 \\
110\end{array}$ & $\begin{array}{l}24.6 \\
23.8 \\
24.6 \\
25.2 \\
25.5 \\
25.5\end{array}$ & $\begin{array}{l}7.28 \\
7.30 \\
7.29 \\
7.29 \\
7.29 \\
7.32\end{array}$ & $\begin{array}{l}7.56 \\
6.12 \\
5.53 \\
5.40 \\
5.29 \\
5.26\end{array}$ & $\begin{array}{l}276 \\
689 \\
818 \\
700 \\
481 \\
378\end{array}$ & $\begin{array}{l}40.6 \\
47.5 \\
48.5 \\
52.3 \\
53.5 \\
53.5\end{array}$ & $\begin{array}{l}210 \\
723 \\
912 \\
801 \\
589 \\
486\end{array}$ & $\begin{array}{l}59.0 \\
8.46 \\
2.54 \\
1.60 \\
0.97 \\
0.77\end{array}$ \\
\hline
\end{tabular}

following salyrgan, the rate of sodium excretion increased to 1,510 microequivalents per minute. The absolute increase in rate of sodium excretion after salyrgan was nearly three times that observed in the control experiment.

For 30 minutes preceding the third experiment and throughout its course as well, the animal inhaled 6.5 per cent carbon dioxide in air through a tight fitting respiratory mask and a two-way
Douglas valve. Following salyrgan, sodium excretion increased from a control level of roughly 200 to a peak value of 800 microequivalents per minute. The extra sodium excretion thus amounted to some 600 microequivalents per minute, a value comparable with that observed in the control experiment, but far less than that observed in the ammonium chloride experiment.

If one compares the values for plasma $\mathrm{pH}$ in 
the three experiments, one may rule out any significant contribution of acidity of the body fluids to the enhancement of diuresis which follows ammonium chloride. Thus plasma $\mathrm{pH}$ was considerably more depressed by the inhalation of carbon dioxide than by the ingestion af ammonium chloride. Similarly urine acidity does not correlate well with the magnitude of the diuretic response. It is true that urine $\mathrm{pH}$ was uniformly low in the ammonium chloride experiment. However, if one compares only the two periods in each experiment in which maximal sodium loss occurred, no convincing correlation between acidity and sodium loss can be established. Thus values of 5.49 and 5.34 were noted in the ammonium chloride experiment, 5.53 and 5.40 in the carbon dioxide experiment, and 5.81 and 5.70 in the control experiment. There remains as the factor of most probable significance ${ }^{4}$ in explaining potentiation, the difference in anion pattern of the blood plasma. More specifically we feel that the absolute level of plasma chloride is the significant

4 The greater filtration rate observed in the ammonium chloride experiment presented in Table I has not been a consistent finding. Although it must have contributed to the marked potentiation of the action of the mercurial diuretic in this experiment, it has not been observed in others in which significant potentiation occurred. factor. Thus ammonium chloride increased the plasma chloride level ${ }^{5}$ and proportionally reduced the plasma bicarbonate concentration without significantly affecting total base or anion concentration. Marked potentiation resulted. Carbon dioxide inhalation on the other hand increased the bicarbonate level without significantly affecting the chloride level. No potentiation was evident. In our entire series of experiments, including those in which sodium bicarbonate was administered, the magnitude of the diuretic response to a standard dose of salyrgan correlated better with the plasma concentration of chloride than with any other factor. However, experimental conditions were such that plasma sodium concentration did not vary significantly. Hence the correlation in an inverse fashion was essentially as good with plasma bicarbonate.

The results of 20 experiments on dogs $R$ and $T$ performed in a manner identical with those presented in Table I are plotted in Figures 1 to 4. Figures 1 and 2 relate the rate of excretion of sodium in microequivalents per minute to time before and after the intravenous administration

5 This animal normally exhibited somewhat higher chloride and lower bicarbonate concentrations in the plasma than does the average animal.

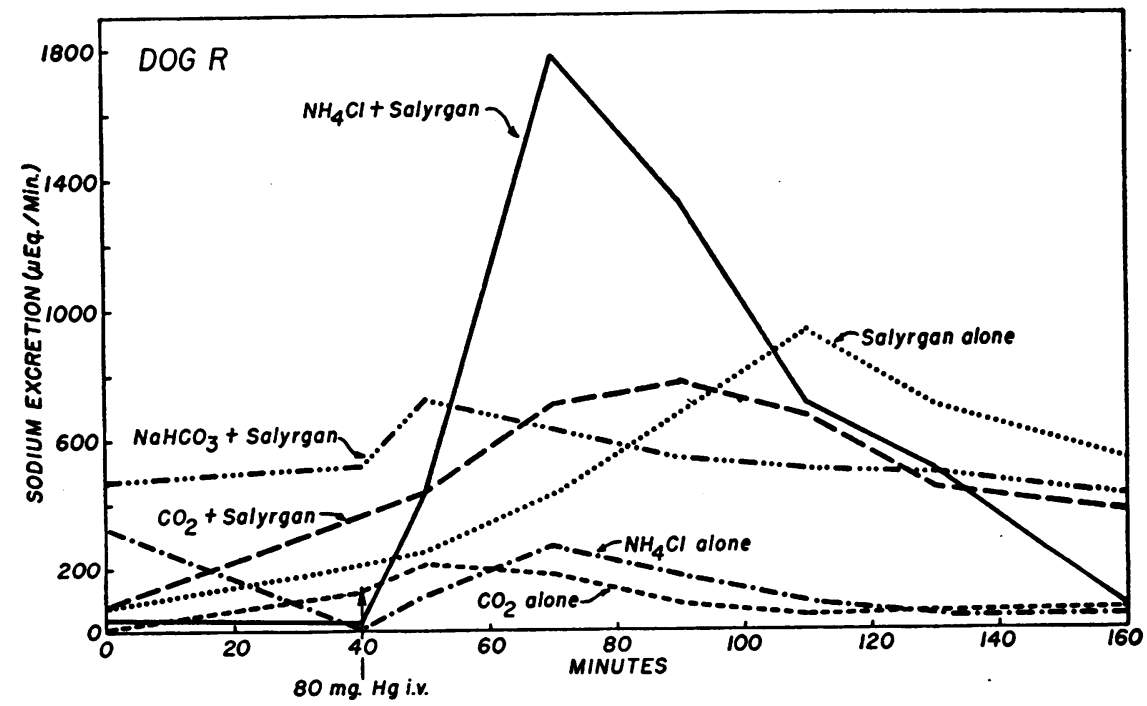

Fig. 1. A Comparison of the Rates of Sodium Excretion under a Variety of Conditions in which Plasma Anion Pattern has bern Altered

The curve labeled Carbon Dioxide plus Salyrgan is the average of three experiments. Salyrgan Alone and Salyrgan plus Ammonium Chloride are each the average of two experiments. Each of the other curves represents one experiment. 


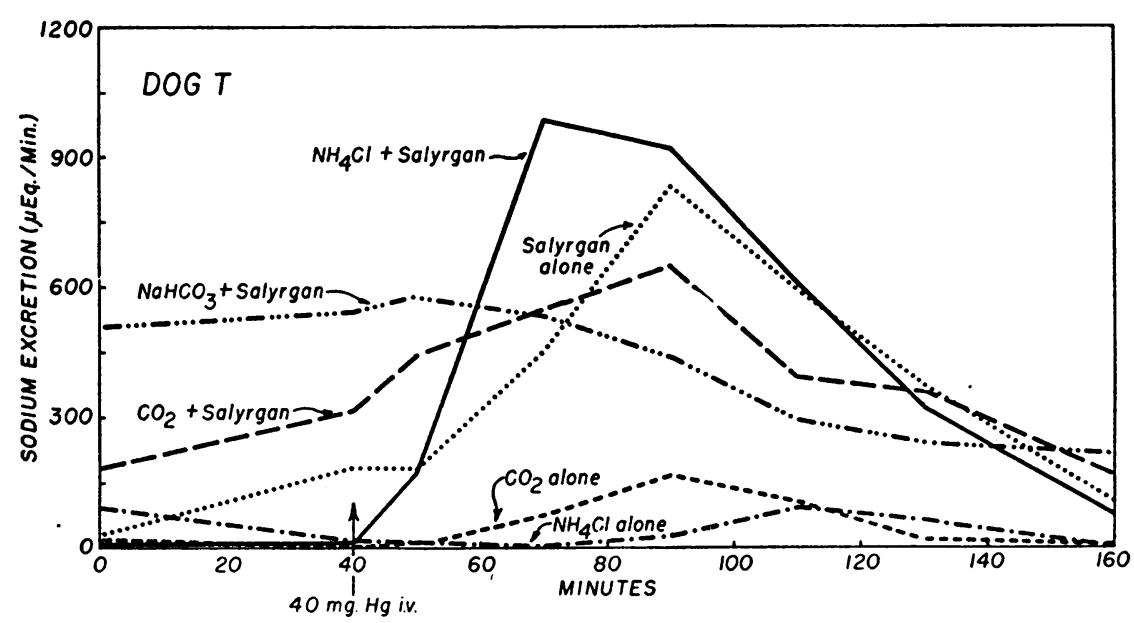

Fig. 2. A Comparison of the Rates of Sodium Excretion under a Variety of Conditions in which Plasma Anion Pattern has been Altered

The curve labeled Salyrgan Alone is the average of three experiments. Carbon Dioxide plus Salyrgan and Ammonium Chloride plus Salyrgan are each the average of two experiments. Each of the other curves represents one experiment.

of salyrgan. Each curve represents the average of one to three similar experiments on one dog, the exact numbers being noted in the legends. The responses to salyrgan alone and to salyrgan during the inhalation of 6 to 8 per cent carbon dioxide are identical within reasonable limits of experimental variability in Dog $R$ (Figure 1 ). In Dog $T$ (Figure 2), the increase in sodium ex-

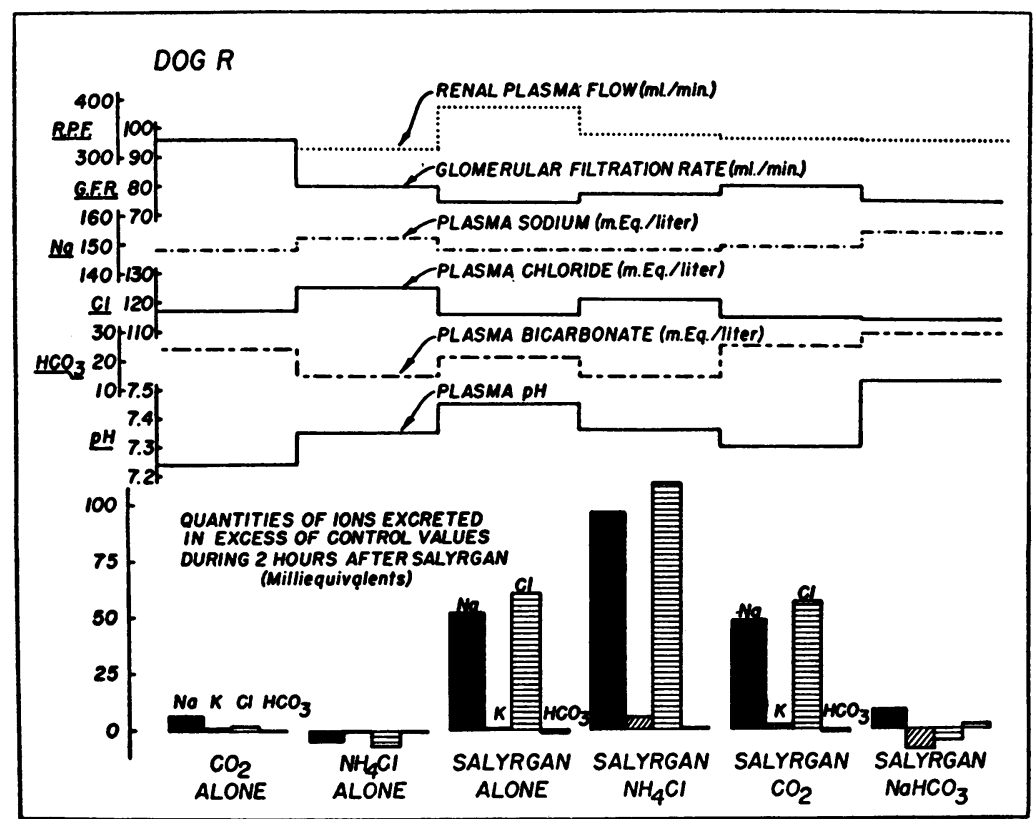

Fig. 3. Electrolyte Excretion, Plasma Concentrations, Glomerular Filtration Rate, and Renal Plasma Flow under a Variety of Conditions in which Plasma Anion Pattern has been Altered

Each block represents total excretion during two hours in excess of the control excretion. 
cretion over and above the control level is actually less during carbon dioxide inhalation, despite marked respiratory acidosis.

In Dog $R$, the response to salyrgan following the administration of ammonium chloride is significantly greater than in control experiments and demonstrates a synergistic type of potentiation of the mercurial by the acidifying agent. In Dog $T$ the synergism is less evident, yet if one considers the magnitude of the increase in sodium excretion over control rates, it is probably real.

The curve designated $\mathrm{NaHCO}_{3}$ plus salyrgan was derived from an experiment in which 15 gms. as controls for the experiments in which salyrgan was given following ammonium chloride and during the inhalation of carbon dioxide.

The data derived from these experiments are summarized in Figures 3 and 4 in such fashion as to permit a comparison of their significant points of difference. In the upper half of each figure are plotted the average values of renal plasma flow, glomerular filtration rate, plasma concentration of sodium, chloride and bicarbonate and plasma $\mathrm{pH}$, noted during the two hours following salyrgan. In the lower half of each figure are shown in block form the milliequivalents of

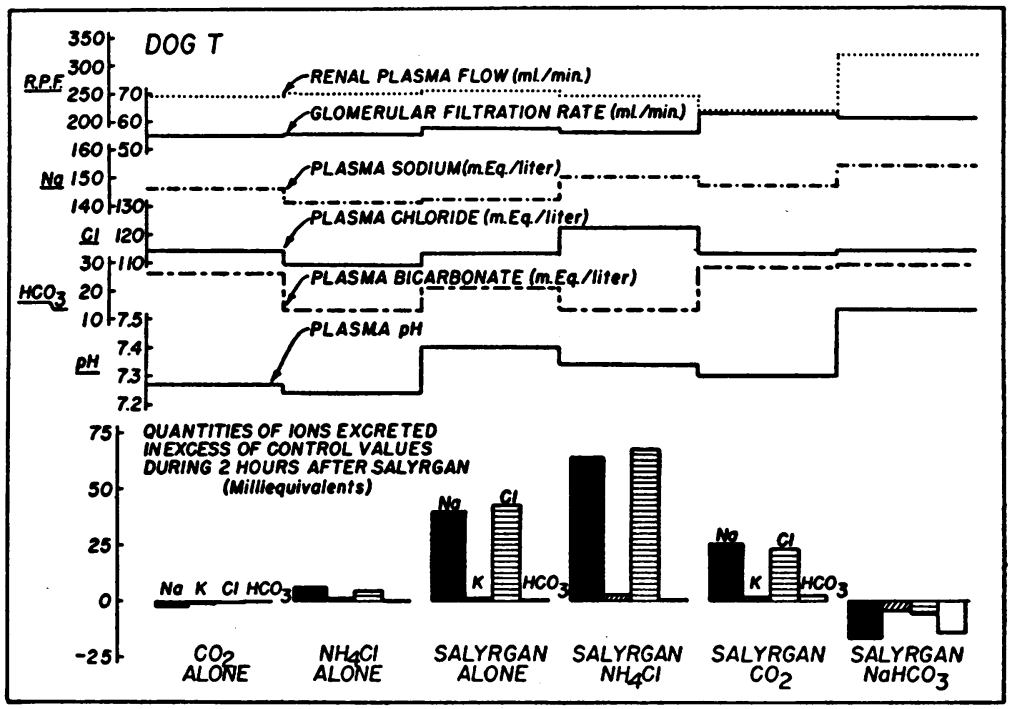

Fig. 4. Electrolyte Excretion, Plasma Concentrations, Glomerular Filtration Rate, and Renal Plasma Flow under a Variety of Conditions in which Plasma Anion Pattern has been Altered

Each block represents total excretion during two hours in excess of the control excretion.

of sodium bicarbonate per day were administered on the three days preceding the experiment and 10 gms. on the day of the experiment. Most of the sodium excreted during the experiment was eliminated as bicarbonate, and the urine was quite alkaline. The plasma level of bicarbonate was elevated and that of chloride depressed. In this experiment and in others like it, salyrgan exhibited little or no diuretic activity, a fact which has been previously noted by other investigators $(5,14)$. The two curves designated $\mathrm{NH}_{4} \mathrm{Cl}$ alone and $\mathrm{CO}_{2}$ alone were derived from experiments in which no mercury was given, and serve sodium, potassium, chloride and bicarbonate excreted during the two hours following salyrgan in excess of what would have been excreted had the control rate been maintained. If a block is above the base line, the rate of excretion of that ion was increased by salyrgan; if below the base line, the rate of excretion declined following the diuretic. This mode of expression more accurately describes synergistic potentiation of the diuretic action of salyrgan by ammonium chloride than does the peak rate of excretion presented in Figures 1 and 2 . It likewise clearly demonstrates abolition of diuresis by the prior administration 
of sodium bicarbonate. It is evident on inspection of the upper part of the chart that of the several variables only two can be correlated with the greater diuretic response to salyrgan following ammonium chloride, namely, reduced plasma bicarbonate and increased plasma chloride concentrations. No causal relationship to increased renal plasma flow and glomerular filtration rate nor to decreased plasma $\mathrm{pH}$ can be demonstrated.

\section{DISCUSSION}

Experiments presented above rule out acidity of the plasma and interstitial fluid as a cause of potentiation of mercurial diuretics by acidifying salts. Thus inhalation of 6 to 8 per cent carbon dioxide, which induces a more severe acidosis than does the ingestion of $10 \mathrm{gms}$. of ammonium chloride, has no effect on salyrgan diuresis.

The data are less conclusive with respect to the relationship between urinary acidity and diuretic efficacy of mercurials. There has been in this series of experiments a marked lability of urinary $\mathrm{pH}$ under all conditions other than those of ammonium chloride acidosis and sodium bicarbonate alkalosis, a fact which renders difficult any assessment of the significance of the acidity of urine. As noted in the discussion of the three experiments presented in Table $I$, there is suggestive evidence that urinary $\mathrm{pH}$ is not a determining factor.

More conclusive evidence for this view is presented in the two experiments outlined in Table II. In these experiments acidosis was induced by the oral administration of ammonium chloride on the day preceding the experiment. On the experimental day, the animal was anesthetized with chloralose (100 mg. per kg.). Saline containing a small amount of neutral sodium phosphate was infused for $2 \frac{1}{2}$ hours prior to and throughout the course of the experiment. After two control periods $160 \mathrm{mg}$. of mercury as mercuhydrin were administered intravenously. The high rate of infusion of saline protects the animal against the acute circulatory collapse which often follows large doses of mercurial diuretics and also produces a prolonged, sustained mercurial diuresis (15). Phosphate was given to stabilize urine $\mathrm{pH}$ and to avoid the disturbing fluctuations often ob-

TABLE II

The effect of an abrupt change in urinary $p H$ during a mercurial diuresis on ion excretion

\begin{tabular}{|c|c|c|c|c|c|c|c|c|c|c|c|c|c|c|c|c|c|c|c|}
\hline \multirow{3}{*}{$\begin{array}{l}\text { Time } \\
\text { mins. }\end{array}$} & \multirow{3}{*}{$\begin{array}{c}\text { Urine } \\
\text { flow } \\
\begin{array}{c}c c . / \\
\text { min. }\end{array}\end{array}$} & \multicolumn{3}{|c|}{$\begin{array}{c}\text { Plasma } \\
\text { concentration }\end{array}$} & \multicolumn{2}{|c|}{ pH } & \multicolumn{3}{|c|}{ Rate of excretion } & \multirow{2}{*}{ Time } & \multirow{2}{*}{$\begin{array}{l}\text { Urine } \\
\text { flow }\end{array}$} & \multicolumn{3}{|c|}{$\begin{array}{c}\text { Plasma } \\
\text { concentration }\end{array}$} & \multicolumn{2}{|c|}{ pH } & \multicolumn{3}{|c|}{ Rate of excretion } \\
\hline & & $\mathrm{Na}$ & $\mathrm{Cl}$ & $\mathrm{HCO}_{3}$ & \multirow{3}{*}{$\begin{array}{c}\text { Plasma } \\
7.28 \\
7.26\end{array}$} & \multirow{3}{*}{$\begin{array}{c}\text { Urine } \\
5.84 \\
5.89\end{array}$} & $\mathbf{N a}$ & $\mathbf{C l}$ & $\mathrm{BHCO}_{2}$ & & & $\mathrm{Na}$ & $\mathbf{C l}$ & $\mathrm{HCO}_{3}$ & \multirow{3}{*}{$\begin{array}{c}\text { Plasma } \\
\begin{array}{c}7.32 \\
7.33\end{array}\end{array}$} & \multirow{3}{*}{$\begin{array}{l}\text { Urine } \\
5.79 \\
5.83\end{array}$} & $\mathrm{Na}$ & $\mathbf{C l}$ & BHCOz \\
\hline & & \multicolumn{3}{|c|}{ milliEq./liter } & & & \multicolumn{3}{|c|}{ microEq./min. } & mins. & $\begin{array}{l}c c_{i} / \\
\text { min. }\end{array}$ & \multicolumn{3}{|c|}{ milliEq./liter } & & & \multicolumn{3}{|c|}{ microEq./min. } \\
\hline $\begin{array}{l}-30-15 \\
-15-0\end{array}$ & $\begin{array}{l}10.8 \\
9.55\end{array}$ & \begin{tabular}{|l|}
149 \\
149
\end{tabular} & $\begin{array}{l}127 \\
127\end{array}$ & $\begin{array}{l}12.9 \\
13.1\end{array}$ & & & $\begin{array}{l}578 \\
870\end{array}$ & $\begin{array}{l}410 \\
730\end{array}$ & $\begin{array}{l}6.38 \\
6.50\end{array}$ & $\begin{array}{l}-30-15 \\
-15-0\end{array}$ & $\begin{array}{l}10.7 \\
8.73\end{array}$ & $\begin{array}{l}158 \\
156\end{array}$ & $\begin{array}{l}129 . \\
130\end{array}$ & $\begin{array}{l}17.2 \\
16.4\end{array}$ & & & $\begin{array}{l}332 \\
272\end{array}$ & $\begin{array}{l}335 \\
252\end{array}$ & $\begin{array}{l}7.45 \\
5.94\end{array}$ \\
\hline \multicolumn{10}{|c|}{$160 \mathrm{mg} . \mathrm{Hg}$ as mercuhydrin } & \multicolumn{10}{|c|}{$160 \mathrm{mg} . \mathrm{Hg}$ as salyrgan } \\
\hline $\begin{array}{r}0-15 \\
15-30 \\
30-45 \\
45-60\end{array}$ & $\begin{array}{l}15.7 \\
15.4 \\
22.9 \\
23.0\end{array}$ & \begin{tabular}{|l|}
151 \\
151 \\
151 \\
151 \\
\end{tabular} & $\begin{array}{l}128 \\
129 \\
125 \\
123\end{array}$ & $\begin{array}{l}\frac{12.9}{12.1} \\
\frac{12.1}{12.1}\end{array}$ & $\begin{array}{l}7.29 \\
7.30 \\
7.30 \\
7.33\end{array}$ & $\begin{array}{l}5.87 \\
5.38 \\
5.19 \\
5.11\end{array}$ & $\begin{array}{l}1860 \\
1980 \\
2990 \\
2940\end{array}$ & $\begin{array}{l}1720 \\
2020 \\
3110 \\
3100\end{array}$ & $\begin{array}{c}10.2 \\
2.62 \\
2.29 \\
1.68\end{array}$ & $\begin{array}{r}0-15 \\
15-30 \\
30-45 \\
45-60 \\
60-75\end{array}$ & \begin{tabular}{|c|}
9.06 \\
6.60 \\
13.3 \\
19.7 \\
21.0
\end{tabular} & $\begin{array}{l}160 \\
157 \\
159 \\
161 \\
161\end{array}$ & \begin{tabular}{|l|}
131 \\
132 \\
136 \\
133 \\
136
\end{tabular} & $\begin{array}{l}12.9 \\
11.3\end{array}$ & $\begin{array}{l}7.40 \\
7.34\end{array}$ & $\begin{array}{l}5.78 \\
5.83 \\
5.30 \\
5.51 \\
5.54\end{array}$ & $\begin{array}{r}363 \\
720 \\
1720 \\
2620 \\
2800\end{array}$ & $\begin{array}{r}254 \\
772 \\
1753 \\
2680 \\
2860\end{array}$ & $\begin{array}{l}5.98 \\
.62 \\
1.73 \\
4.14 \\
6.10\end{array}$ \\
\hline \multicolumn{10}{|c|}{ Carbonic anhydrase inhibitor, $10 \mathrm{mg} . / \mathrm{kg}$. } & \multicolumn{10}{|c|}{ Carbonic anhydrase inhibitor, $20 \mathrm{mg} . / \mathrm{kg}$. } \\
\hline $\begin{array}{c}60-75 \\
75-90 \\
90-105 \\
105-120\end{array}$ & $\begin{array}{l}24.6 \\
20.3 \\
18.3 \\
17.3\end{array}$ & \begin{tabular}{|l|}
149 \\
149 \\
151 \\
151
\end{tabular} & $\begin{array}{l}123 \\
122 \\
122\end{array}$ & \begin{tabular}{l|}
12.2 \\
113.7 \\
13.8 \\
14.4
\end{tabular} & $\begin{array}{l}7.34 \\
7.28 \\
7.27 \\
7.26\end{array}$ & $\begin{array}{l}6.28 \\
6.56 \\
6.40 \\
6.31\end{array}$ & $\begin{array}{l}3310 \\
2750 \\
2560 \\
2470\end{array} \mid$ & $\begin{array}{l}3270 \\
2520 \\
2320 \\
2340\end{array} \mid$ & $\begin{array}{c}68.6 \\
125 \\
69.4 \\
52.6\end{array}$ & $\begin{array}{c}75-90 \\
90-105 \\
105-120\end{array}$ & $\begin{array}{l}22.5 \\
22.2 \\
20.4\end{array}$ & $\begin{array}{l}162 \\
161 \\
164\end{array}$ & $\begin{array}{l}136 \\
135 \\
136\end{array}$ & $\begin{array}{l}13.0 \\
13.7\end{array}$ & $\begin{array}{l}7.33 \\
7.28\end{array}$ & $\begin{array}{l}6.53 \\
6.61 \\
6.52\end{array}$ & $\begin{array}{l}3120 \\
3080 \\
2780\end{array} \mid$ & $\left|\begin{array}{l}2990 \\
2910 \\
2660\end{array}\right|$ & $\begin{array}{c}93.0 \\
110 \\
72.8\end{array}$ \\
\hline \multicolumn{10}{|c|}{ BAL, $1 \mathrm{cc}$. } & \multicolumn{10}{|c|}{ BAL, 1 cc. } \\
\hline $\begin{array}{l}120-135 \\
135-150 \\
150-165\end{array}$ & $\begin{array}{c}12.4 \\
5.27 \\
4.69\end{array}$ & \begin{tabular}{|l|}
149 \\
150 \\
149
\end{tabular} & \begin{tabular}{|l|l|}
119 \\
123 \\
123
\end{tabular} & $\begin{array}{l}13.3 \\
13.6 \\
13.0\end{array}$ & $\begin{array}{l}7.28 \\
7.24 \\
7.24\end{array}$ & $\begin{array}{l}6.41 \\
6.95 \\
6.96\end{array}$ & $\begin{array}{r}1930 \\
895 \\
740 \\
\end{array}$ & $\begin{array}{r}1740 \\
453 \\
302\end{array}$ & $\begin{array}{l}55.7 \\
140 \\
139\end{array}$ & $\begin{array}{l}120-135 \\
135-150 \\
150-165\end{array}$ & \begin{tabular}{c|}
15.9 \\
9.21 \\
9.57
\end{tabular} & $\begin{array}{l}168 \\
167 \\
170\end{array}$ & $\begin{array}{l}137 \\
139 \\
142\end{array}$ & 13.0 & 7.24 & $\begin{array}{l}6.50 \\
6.76 \\
6.82\end{array}$ & $\begin{array}{r}2040 \\
900 \\
834\end{array}$ & \begin{tabular}{|l|}
1907 \\
683 \\
616
\end{tabular} & $\begin{array}{l}58.2 \\
75.8 \\
85.6\end{array}$ \\
\hline
\end{tabular}


served when the urine is poorly buffered. Urine flow and sodium excretion rose rapidly to reach a plateau 30 to 40 minutes after the mercurial. A priming dose of the carbonic anhydrase inhibitor (2-acetylamino-1,3,4-thiadiazole-5-sulfonamide ${ }^{\circ}$ [10 to $20 \mathrm{mg}$. per $\mathrm{kg}$.]) was given intravenously to shift urine $\mathrm{pH}$ rapidly toward an alkaline reaction, and the inhibitor was also infused at a rate of 2 to $4 \mathrm{mg}$. per minute. Finally, $1 \mathrm{cc}$. of BAL was given intramuscularly to block the action of the mercurial diuretic. It is evident that a rapid change in urine $\mathrm{pH}$ in the absence of any significant change in the composition of the plasma was without effect on the action of the mercurial diuretic. Thus the peak urine flows and peak rates of excretion of sodium and chloride obtained after the mercurial were not depressed following the administration of the inhibitor despite a significant increase in urine $\mathrm{pH}$.

The inherent natriuretic action of the inhibitor is represented by the increased excretion of bicarbonate. Blockage of exchange of hydrogen ion for sodium ion leads to increased excretion of sodium equivalent to the increased excretion of bicarbonate. It is evident from Table II that this quantity constitutes an insignificant fraction of total sodium excretion. BAL, which abolishes the mercurial natriuresis and chloruresis, returns the excretion of sodium and chloride toward control levels. There remains superimposed the inherent natriuretic action of the inhibitor.

In all of our experiments the magnitude of the

6 We wish to thank American Cyanamid Company for their generous supply of the carbonic anhydrase inhibitor.

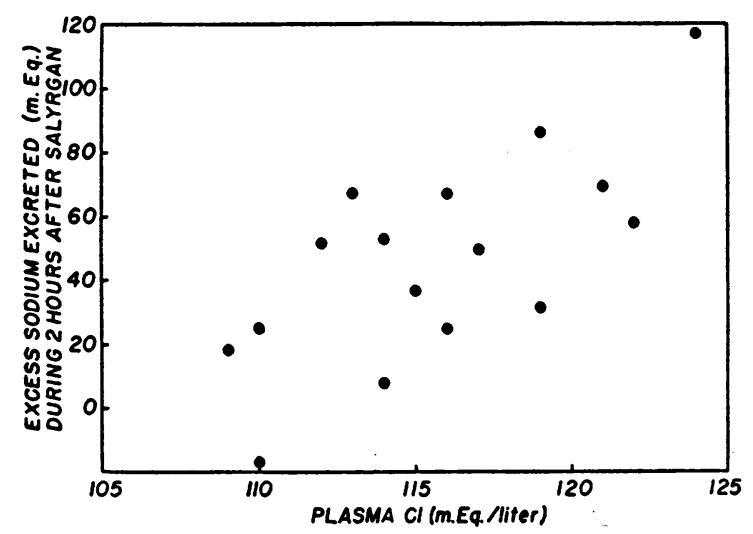

Fig. 5. Relationship between Plasma Chloride Concentration and the Effectiveness of Salyrgan in Producing Sodium Diuresis

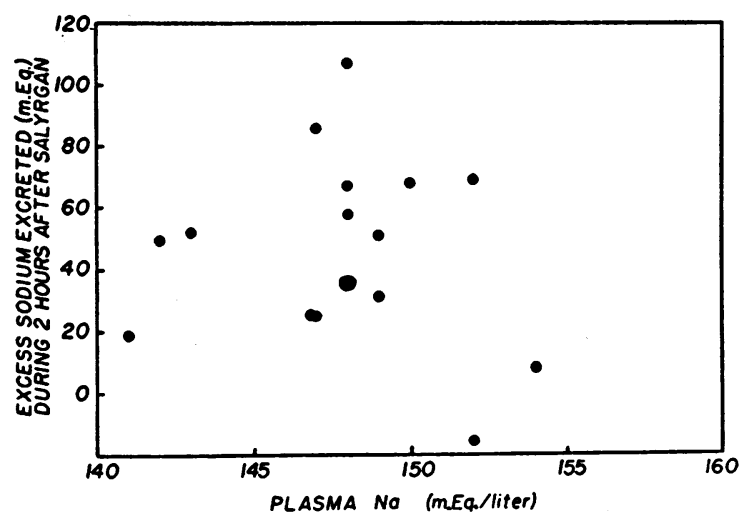

Fig. 6. Relationship between Plasma Sodium Concentration and the Effectiveness of Salyrgan in Producing Sodium Diuresis

diuretic response to salyrgan appeared to be directly related to the plasma chloride concentration and inversely related to the plasma bicarbonate concentration. Under the condition of our experiments, no significant relationship exists between plasma sodium concentration and mercurial response. These facts are illustrated in Figures $\mathbf{5}$ and 6 in which excess sodium excreted during the two hours after salyrgan is plotted against the average concentrations during the same period of plasma chloride and plasma sodium. Each point represents a single experiment such as those presented in Table I. The coefficient of correlation for the 16 pairs of observations using the mean concentration values and the total excess excretion values after administration of salyrgan, shows the correlation between plasma chloride concentration and excess sodium excretion to be $r=$ $+.70(p=.0025)$. This is a statistically significant degree of correlation. The correlation between plasma sodium concentration and excess sodium excretion is $\mathrm{r}=-.13(\mathrm{p}=>.6,<.7)$. This is not significantly different from zero correlation. In general an increase in plasma chloride induced by ammonium chloride was associated with an essentially equivalent reduction in plasma bicarbonate. It is, therefore, obvious that if sodium excretion is directly related to the plasma concentration of one of these anions, it must be inversely related to that of the other.

We feel that the relationship to plasma chloride is the significant one, and that if mercury specifically blocks one ion absorptive mechanism, that mechanism is the one for chloride absorption. In- 
creased sodium excretion following mercurial diuretics is thus a more or less passive consequence of increased chloride elimination. This view is based on the following facts: (a) After salyrgan the excretion of chloride regularly exceeds that of sodium. This can be seen in Table I and Figures 3 and 4 and has previously been noted by Blumgart and his co-workers $(8,16)$. Others $(2,4,17)$ have correlated the efficacy of a mercurial diuretic with the plasma chloride concentration. (b) Bicarbonate excretion is not increased in mercurial diuresis (cf. Figures 3 and 4). Were sodium reabsorption specifically blocked, one would anticipate that the excretion of both bicarbonate and chloride would be increased, rather than that of chloride alone. Furthermore, the plasma concentrations of chloride and bicarbonate reflect this discrepant loss of chloride. During the course of a mercurial diuresis there is frequently a fall in plasma chloride and a rise in plasma bicarbonate with no change in plasma sodium concentration (Table $I,[6,8,14$, 18]).

Hypochloremia has been cited as one cause of resistance of patients to mercurial diuretics (14); others have not distinguished between hypochloremia and hyponatremia $(2,9)$. Elevation of plasma chloride by administration of sodium chloride or ammonium chloride has been shown to restore the response of such individuals to mercury $(14,17,19)$. Our results are in agreement with such a view, and extend it by suggesting that potentiation of diuretic action by ammonium chloride is a consequence of the hyperchloremia induced.

Although we have not studied other acidifying agents known to potentiate mercurial diuretics, we would anticipate that a similar explanation could account for their effects. The action of calcium chloride would obviously parallel that of ammonium chloride for both substitute chloride for bicarbonate in the body fluids (20-22). Ammonium nitrate not only increases the plasma concentration of nitrate, but to some degree causes the retention of chloride "at the expense of bicarbonate" (3-5). It is probable that ammonium sulfate produces the same effect (22). Furthermore, it has been shown that when the administration of nitrate causes a fall in plasma chloride, mercurial diuresis is reduced (4). A single explanation could thus account for the action of these several acidifying agents, namely, elevation of plasma chloride level. Since the greatest increase in plasma chloride results from the ingestion of ammonium chloride, it is not surprising that it is the most effective of the potentiating agents and the one which is commonly employed clinically.

\section{SUM MARY}

In experiments on normal dogs, it has been observed that the administration of $10 \mathrm{gms}$. of ammonium chloride on the day preceding salyrgan, significantly potentiates the action of the mercurial diuretic. This potentiation is not a result of increased acidity of the urine and body fluid induced by the acidifying agent. Rather it is a result of an alteration in anion pattern of the body fluids, namely, a substitution of chloride for bicarbonate. It is suggested that mercurial diuretics specifically block chloride absorption and that the potentiation of diuretic action by ammonium chloride is a consequence of the hyperchloremia induced.

\section{REFERENCES}

1. Keith, N. M., Barrier, C. W., and Whelan, M., The diuretic action of ammonium chloride and novasurol, in cases of nephritis with edema. J. A. M. A., 1925, 85, 799.

2. Keith, N. M., and Whelan, M., A study of the action of ammonium chloride and organic mercury compounds. J. Clin. Invest., 1926-27, 3, 149.

3. Keith, N. M., Whelan, M., and Bannick, E. G., The action and excretion of nitrates. Arch. Int. Med., 1930, 46, 797.

4. Binger, M. W., and Keith, N. M., The effect of diuretics in different types of edema. J. A. M. A., 1933, $101,2009$.

5. Ethridge, C. B., Myers, D. W., and Fulton, M. N., Modifying effect of various inorganic salts on the diuretic action of salyrgan. Arch. Int. Med., 1936, $57,714$.

6. Fulton, M. N., Van Auken, H. A., Parsons, R. I., and Davenport, L. F., The comparative effect of various diuretics in dogs with special reference to the excretion of urine, chloride, and urea. J. Pharmacol. \& Exper. Therap., 1934, 50, 223.

7. Newman, E. V., Therapeutic Conference. The treatment of heart failure. II. The use of diuretics. Bull. Johns Hopkins Hosp., 1947, 81, 430.

8. Blumgart, H. L., Gilligan, D. R., and Volk, M. C., Action of diuretic drugs. II. Effect of diuretic 
drugs on the acid-base equilibrium of the blood in patients with cardiac edema, in Medical Papers Dedicated to H. A. Christian. Waverly Press, Baltimore, Md., 1936, p. 191.

9. Schroeder, H. A., Renal failure associated with low extracellular sodium chloride; low salt syndrome. J. A. M. A., 1949, 141, 117.

10. Van Slyke, D. D., and Sendroy, J., Carbon dioxide factors for the manometric blood gas apparatus. J. Biol. Chem., 1927, 73, 127.

11. Van Slyke, D. D., and Hiller, A., Application of Sendroy's iodometric chloride titration to protein containing fluids. J. Biol. Chem., 1947, 167, 107.

12. Bonsnes, R. W., and Taussky, H. H., On the colorimetric determination of creatinine by the Jaffe reaction. J. Biol. Chem., 1945, 158, 581.

13. Smith, H. W., Finkelstein, N., Aliminosa, L., Crawford, B., and Graber, M., The renal clearances of substituted hippuric acid derivatives and other aromatic acids in dog and man. J. Clin. Invest., 1945, 24, 388.

14. Schwartz, W. B., and Wallace, W. M., Observations on electrolyte balance during mercurial diuresis in congestive heart failure. J. Clin. Invest., 1950, $29,844$.
15. Duggan, J. J., and Pitts, R. F., Studies on diuretics. I. The site and action of mercurial diuretics. J. Clin. Invest., 1950, 29, 365.

16. Blumgart, H. L., Gilligan, D. R., Levy, R. C., and Brown, M. G., Action of diuretic drugs : I. Action of diuretics in normal persons. Arch. Int. Med., 1934, 54, 40.

17. Evans, W. A., The effect of changes in salt and water metabolism upon salyrgan diuresis (with special reference to the effect of permanent bile fistula), in Medical Papers Dedicated to W. A. Christian. Waverly Press, Baltimore, Md., 1936, p. 204.

18. Crawford, J. H., and McIntosh, J. F., Observations on the use of novasurol in edema due to heart failure. J. Clin. Invest., 1924, 1, 333.

19. Goldring, W., Edema in congestive heart failure; effectiveness of diuretics as guide to prognosis. Arch. Int. Med., 1929, 44, 465.

20. Haldane, J. B. S., Hill, R., and Luck, J. M., Calcium chloride acidosis. J. Physiol., 1923, 57, 301.

21. Haldane, J. B. S., Experiments on the regulation of the blood's alkalinity. J. Physiol., 1921, 55, 265.

22. Gamble, J. L., Blackfan, K. D., and Hamilton, B., A study of the diuretic action of acid producing salts. J. Clin. Invest., 1924-25, 1, 359. 